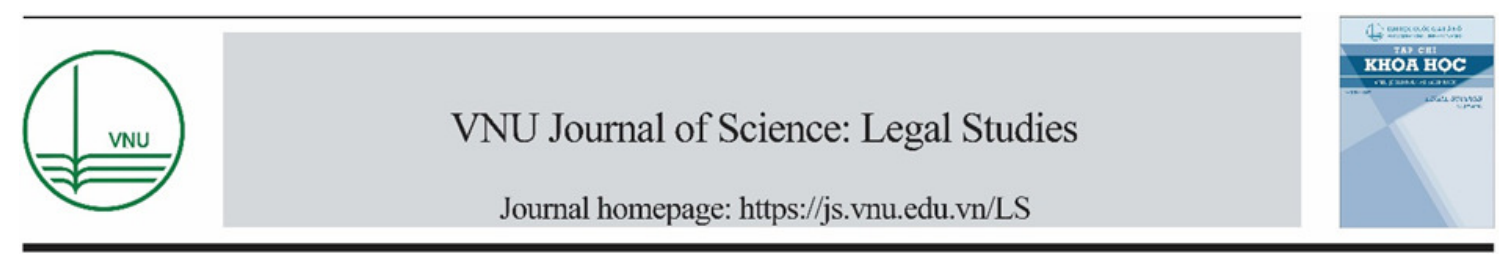

Review Article

\title{
Protection of Human Rights of the Accused in the Process of Criminal Investigation
}

\author{
Tran Thi Thu Hien* \\ Hanoi Law University, 87 Nguyen Chi Thanh, Dong Da, Hanoi, Vietnam \\ Received 13 January 2019 \\ Revised 18 February 2019; Accepted 15 March 2019
}

\begin{abstract}
The investigation in criminal procedure is deemed an important stage with respect to human rights guarantee. During this period, the accused, who is in the most unfavorable position, should be paid attention to and protected. Therefore, this article aims to clarify the scientific legal aspects of human rights of the accused in criminal investigation, indicate some shortcomings in the provisions of Criminal Procedure Code 2015 to offer legal solutions to strengthen the human rights guarantee for the accused in criminal investigation.
\end{abstract}

Keywords: Criminal procedure, the accused, human rights, the investigation.

\footnotetext{
${ }^{*}$ Corresponding author.

E-mail address: tranhien9984@yahoo.com

https://doi.org/10.25073/2588-1167/vnuls. 4205
} 


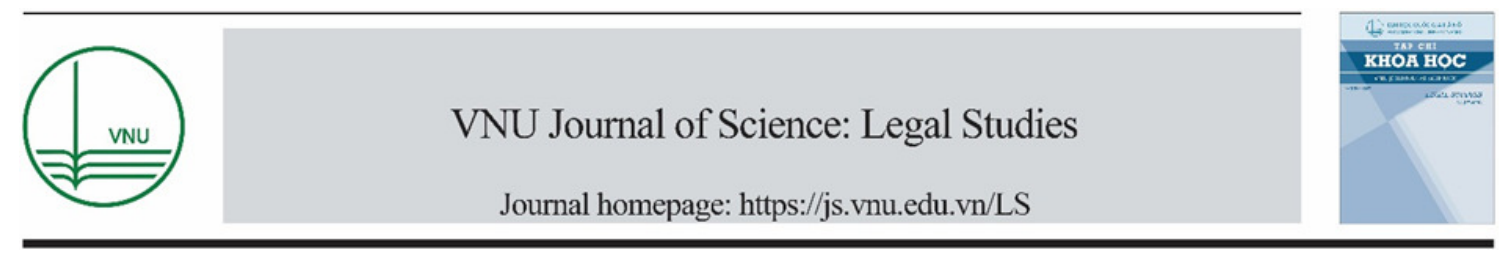

\title{
Bảo đảm quyền con người của bị can trong giai đoạn điều tra vụ án hình sự
}

\author{
Trần Thị Thu Hiền* \\ Truờng Đại học Luật Hà Nội, 87 Nguyễn Chí Thanh, Đống Đa, Hà Nội, Việt Nam \\ Nhận ngày 13 tháng 01 năm 2019 \\ Chỉnh sửa ngày 18 tháng 02 năm 2019; Chấp nhận đăng ngày 15 tháng 03 năm 2019
}

Tóm tắt: Điều tra trong tố tụng hình sự (TTHS) được xem là giai đoạn xung yếu ở khía cạnh bảo đảm quyền con người. Trong giai đoạn này, bị can là đối tượng yếu thế nhất cần được quan tâm, bảo vệ. Vì vậy, bài viết tập trung làm rõ các khía cạnh pháp lí khoa học về bảo đảm quyền con người của bị can trong giai đoạn điều tra vụ án hình sự, chỉ ra một số vấn đề hạn chế, vướng mắc trong quy định của Bộ luật TTHS năm 2015, đưa ra các giải pháp về pháp luật nhằm tăng cường bảo đảm quyền con người của người bị can trong giai đoạn điều tra vụ án hình sự.

Từ khóa: Tố tụng hình sự, bị can, quyền con người, giai đoạn điều tra.

\section{1. Đặt vấn đề}

Bảo đảm quyền con người của bị can trong quá trình giải quyết vụ án hình sự được đặt ra kể từ khi đất nước ta thực hiện cải cách tư pháp theo Nghị quyết 49/NQ-TW của Bộ Chính trị về Chiến lược cải cách tư pháp đến năm 2020 , đặc biệt từ sau khi Hiến pháp năm 2013 ra đời với qui định tại Chương 2 về quyền con người, quyền và nghĩa vụ cơ bản của công dân, trong đó nhấn mạnh đến vai trò của nhà nước đối với việc bảo đảm quyền con người và "Quyền con người, quyền công dân chỉ có thể bị hạn chế theo quy định của luật trong trường hợp cần

\footnotetext{
* Tác giả liên hệ.

Địa chỉ email: tranhien9984@yahoo.com

https://doi.org/10.25073/2588-1167/vnuls. 4205
}

thiết vì lí do quốc phòng, an ninh quốc gia, trật tự, an toàn xã hội, đạo đức xã hội, sức khỏe của cộng đồng $[1$, tr.14 ]. Trên tinh thần đó, bài viết này tập trung làm rõ cơ sở của việc bảo đảm quyền của bị can; nội dung, cơ chế và những yếu tố ảnh hưởng đến việc bảo đảm quyền con người của bị can; các kiến nghị tăng cường bảo đảm quyền con người của bị can trong giai đoạn điều tra giải quyết vụ án ở nước ta hiện nay.

\section{Tính tất yếu và cơ sở của việc bảo đảm quyền con người của bị can trong quá trình giải quyết vụ án hình sự}

Bảo đảm quyền con người của bị can là xu thế của thời đại văn minh ở mọi quốc gia mặc dù họ là người bị cáo buộc phạm tội. Bản chất hoạt động tố tụng hình sự là hoạt động thực 
hiện quyền lực Nhà nước mà trong đó luôn có sự xung đột của hai nhóm lợi ích- lợi ích công và lợi ích cá nhân. Lợi ích công thể hiện ở nhiệm vụ của tố tụng hình sự là phát hiện chính xác và xử lí nghiêm minh người phạm tội còn lợi ích cá nhân thể hiện ở nhiệm vụ của tố tụng hình sự là phải bảo đảm cho các quyền cơ bản của công dân không bị hạn chế trái pháp luật [2, tr.33]. Tố tụng hình sự của một nhà nước văn minh sẽ giải quyết đúng đắn quan hệ pháp lí giữa hai nhóm lợi ích này, tức là vừa bảo đảm phát hiện, xử lí nghiêm minh tội phạm, vừa bảo đảm quyền con người đặc biệt là những người bị cáo buộc về hình sự. Những người bị cáo buộc về hình sự trong đó có bị can trước hết là con người nên phải được hưởng quyền con người cơ bản như những người khác trong xã hội, tuy nhiên do địa vị tố tụng của họ, họ có thể bị hạn chế một số quyền con người, sự hạn chế này do luật định.

Bảo đảm quyền con người của bị can không những thể hiện sự tôn trọng tính mạng, sức khỏe, danh dự nhân phẩm của họ mà còn góp phần quan trọng vào việc giải quyết vụ án khách quan, công bằng. Tính mạng, sức khỏe, danh dự, nhân phẩm là giá trị nội tại vốn có của con người, là vấn đề có ý nghĩa quan trọng hàng đầu đối với con người. Bảo đảm quyền con người của bị can là sự tôn trọng, đề cao các giá trị này của con người. Bên cạnh đó, giai đoạn điều tra trong tố tụng hình sự thẩm vấn với các đặc điểm bán công khai, sự tranh tụng và bình đẳng giữa hai bên còn hạn chế thì bảo đảm quyền con người của bị can giữ vai trò như đối trọng để hạn chế sai lầm và vi phạm pháp luật trong hoạt động của các cơ quan có thẩm quyền tiến hành tố tụng, bảo đảm tính nghiêm minh của pháp luật. Mặt khác, bảo đảm quyền con người của bị can là nền tảng, cơ sở cho sự bình đẳng giữa bên buộc tội và bên gỡ tội trong tố tụng hình sự - đó là biểu hiện của công bằng trong tố tụng hình sự.

Bảo đảm quyền con người của bị can góp phần bảo vệ công lí. Công lí là sự công bằng, đúng đắn, lẽ phải, cái lẽ phù hợp với đạo lí và lợi ích chung của xã hội. Công lí và quyền con người là hai vấn đề có mối quan hệ biện chứng với nhau. Khi công lí được thực hiện thì đồng thời quyền con người cũng được bảo đảm, ngược lại, khi quyền con người được bảo đảm thì công lí cũng được thực thi. Do vậy, khi quyền con người của bị can được bảo đảm thực hiện thì sự công bằng, bình đẳng của bị can cũng được thực thi, bị can được hưởng quyền lợi mà mình đáng được hưởng, mọi hành vi phương hại đến quyền và lợi ích hợp pháp của bị can đều bị xử lí nghiêm minh, đó chính là biểu hiện của công lí trong tố tụng hình sự.

Bảo đảm quyền con người của bị can được dựa trên các văn kiện quốc tế về quyền con người mà Việt Nam là thành viên. Từ năm 1977, Việt Nam gia nhập Liên Hợp quốc và xúc tiến việc tham gia các điều ước quốc tế về nhân quyền và quyển con người của tổ chức này. Hiện nay, Việt Nam đã trở thành thành viên của nhiều điều ước quốc tế quan trọng về nhân quyền và quyền con người như Công ước quốc tế về các quyền dân sự chính trị năm 1966, Công ước quốc tế của Liên Hợp quốc về chống tra tấn và các hình thức đối xử hoặc trừng phạt tàn bạo, vô nhân đạo hoặc hạ nhục con người, Công ước về quyền trẻ em 1989... Thực hiện yêu cầu của các Công ước, Việt Nam từng bước nội luật hóa các quy định trong Công ước vào pháp luật của mình, đặc biệt là pháp luật tố tụng hình sự, tạo ra cơ sở pháp lí để bảo đảm tốt hơn nữa quyền con người của bị can trong quá trình giải quyết vụ án hình sự.

Bảo đảm quyền con người của bị can là định hướng của đường lối chính sách của Đảng và nhà nước ta trong giai đoạn hiện nay. Nhiệm vụ phát triển và bảo vệ đất nước, yêu cầu xây dựng nhà nước pháp quyền Việt Nam XHCN đòi hỏi phải tiến hành cải cách tư pháp và vấn đề bảo đảm quyền con người, quyền công dân trong TTHS được Đảng ta đặc biệt quan tâm. Nghị quyết 49/NQ-TW của Bộ Chính trị về Chiến lược cải cách tư pháp đến năm 2020 khẳng định "Đòi hỏi của nhân dân và xã hội đối với các cơ quan tư pháp ngày càng cao. Các cơ quan tư pháp phải thực sự là chỗ dựa cho nhân dân trong việc bảo vệ công lí, quyền con người, đồng thời phải là công cụ hữu hiệu để bảo vệ pháp luật và pháp chế xã hội chủ nghĩa, đấu tranh có hiệu quả với các loại tội phạm và vi phạm pháp luật". 
Bảo đảm quyền con người của bị can là sự hiện thực hóa các qui định của Hiến pháp năm 2013 về quyền con người. Hiến Pháp năm 2013 nhấn mạnh và đề ra những yêu cầu về dân chủ, pháp quyền, tôn trọng và bảo vệ, bảo đảm quyền con người. Cụ thể hóa yêu cầu Hiến pháp, trong tố tụng hình sự, vấn đề bảo đảm quyền con người được coi là trục xoay của toàn bộ các hoạt động TTHS. Trong đó, bảo đảm quyền con người của bị can chiếm một vị trí quan trọng, bởi lẽ bị can là một trong nhóm yếu thế cần được ưu tiên bảo vệ trong tố tụng hình sự.

\section{Nội dung quyền con người của bị can trong giai đoạn điều tra vụ án hình sự}

Quyền con người của bị can trong giai đoạn điều tra vụ án hình sự gồm hai nhóm quyền: Quyền an toàn thân thể, danh dự, nhân phẩm của cá nhân và quyền được xét xử công bằng.

\subsection{Nhóm quyền an toàn thân thể, danh dư, nhân phấm của bị can}

Một là, quyền sống.

Quyền sống của con người được quy định tại Điều 3 UDHR và Điều 6 ICCPR năm 1966 "Mọi người đều có quyền cố hữu là được sống. Quyền này phải được pháp luật bảo vệ. Không ai có thể bị tước mạng sống một cách tùy tiện". Quyền sống là quan trọng nhất của con người. Quyền sống của bị can không nên hiểu theo nghĩa hẹp chỉ là sự toàn vẹn về tính mạng. Quyền này bao gồm cả những khía cạnh nhằm bảo đảm sự tồn tại của con người. Khía cạnh thứ nhất là xóa bỏ các nguy cơ đe đọa quyền sống. Khía cạnh thứ hai của quyền sống là bảo đảm các điều kiện tồn tại của con người đối với người bị tước tự do. Đối với bị can, khía cạnh thứ hai này thể hiện rõ nét trong trường hợp bị can bị áp dụng biện pháp ngăn chặn tạm giam. Khi bị can bị tạm giam, phải bảo đảm các điều kiện về chỗ ở (thoáng mát, đủ ánh sáng, điều kiện vệ sinh sạch sẽ), chế độ ăn, uống (đồ ăn với giá trị dinh dưỡng phù hợp cho sức khỏe vào thời gian nhất định, nước uống phải có sẵn), y tế (có cán bộ y tế có đủ trình độ, người bị tạm giam bị ốm và cần điều trị đặc biệt phải được chuyển đến bệnh viện)...

Hai là, quyền bất khả xâm phạm về thân thể, danh dự, nhân phẩm.

Đối với con người, tự do cá nhân là vấn đề quan trọng, có tính chất quyết định đến đời sống họ. Xét về mặt ngôn ngữ học, tự do là một phạm trù triết học chỉ khả năng biểu hiện ý chí, hành động theo ý muốn của mình trên cơ sở nhận thức quy luật phát triển của tự nhiên và xã hội [3, tr.1710]. Ở khía cạnh pháp lí, theo Montesquieu, trong một đất nước có luật pháp, tự do chỉ có thể là được làm những cái nên làm và không bị ép buộc làm điều không nên làm. Tự do là quyền được làm tất cả những điều mà luật cho phép [4, tr.99]. Như vậy, tự do là quyền của con người và quyền đó chỉ bị giới hạn bởi pháp luật. Trong đó, tự do thân thể con người là một trong những giá trị của con người cần được bảo đảm ở mức độ cao nhất. Nhân phẩm và danh dự con người là những giá trị nội tại vốn có, là cái làm nên sự khác biệt, là bước tiến vượt bậc của con người với phần còn lại của thế giới tự nhiên $[5$, tr.30]. Vì vậy, quyền bất khả xâm phạm về thân thể, danh dự nhân phẩm là quyền con người được ghi nhận và bảo vệ. Điều 1 UDHR tuyên bố: "Tất cả mọi người sinh ra đều được tự do và bình đẳng về nhân phẩm và quyền. Mọi con người đều được tạo hóa ban cho lí trí và lương tâm và cần phải đối xử với nhau trong tình bằng hữu". Điều 3 UDHR năm 1948 khẳng định "Mọi người đều có quyền sống, quyền tự do và an toàn cá nhân". Tiếp đến, Điều 10 ICCPR quy định: "Những người bị tước tự do phải được đối xử nhân đạo với sự tôn trọng nhân phẩm vốn có của con người”. Đối với bị can, người có nguy cơ bị áp dụng các biện pháp điều tra, ngăn chặn ảnh hưởng đến tự do thân thể thì việc tôn trọng và thực hiện quyền này là vấn đề cơ bản, thiết yếu. Quyền bất khả xâm phạm về thân thể, danh dự, nhân phẩm của bị can bao hàm hai nội dung: (1) Hoạt động tố tụng hình sự phải tiến hành trên cơ sở tôn trọng tự do thân thể, nhân phẩm danh dự của bị can. Việc hạn chế các quyền nói trên chỉ được tiến hành trên cơ sở quy định pháp luật; (2) Nghiêm cấm mọi hành vi xâm phạm đến tính mạng, sức khỏe, danh dự, 
nhân phẩm của bị can. Mọi hành vi trái pháp luật xâm phạm đến tính mạng, sức khỏe, danh dự, nhân phẩm của bị can đều bị xử lí theo pháp luật.

Ba là, quyền bảo vệ để khỏi bị bắt, giam giữ tùy tiện.

Trong quá trình quản lí xã hội, có những trường hợp Nhà nước phải tiến hành biện pháp ngăn chặn một người nào đó thực hiện hành vi xâm phạm đến quyền và lợi ích của cá nhân khác nhằm mục đích duy trì trật tự xã hội, bảo vệ lợi ích của Nhà nước, của cộng đồng. Tuy nhiên, con người ai sinh ra cũng có quyền được sống trong một môi trường an toàn, trong đó có sự an toàn về mặt pháp lí. Vì vậy, sẽ là một xã hội bất công nếu ai cũng có thể bị bắt, cách ly ra khỏi xã hội bất cứ lúc nào mà không có lí do chính đáng. Do đó, quyền bảo vệ để khỏi bị bắt, giam giữ tùy tiện là quyền cơ bản, thiết thân của con người. Quyền này là cốt lõi của tự do và an ninh cá nhân. Quyền được bảo vệ không bị bắt giam giữ tùy tiện được quy định tại Điều 9 UDHR: "Không ai bị bắt, giam giữ hay lưu đày một cách tùy tiện" và được cụ thể hóa, chi tiết hóa tại Điều 9 ICCPR năm 1966. Quyền được bảo vệ không bị bắt, giam giữ tùy tiện của bị can bao gồm các nội dung sau: (1) Mọi người đều có quyền hưởng tự do an toàn cá nhân, không ai bị tước tự do trừ trường hợp việc tước tự do đó là có lí do và theo đúng thủ tục mà luật pháp quy định; (2) Bất cứ người nào bị bắt giữ đều phải được thông báo về lí do họ bị bắt và phải được thông báo không chậm chễ về sự buộc tội đối với họ; (3) Bất cứ người nào bị bắt giữ đều phải được đưa ra sớm trước cơ quan tài phán có thẩm quyền và xét xử trong thời hạn hợp lí hoặc trả tự do.

Bốn là, quyền bảo vệ không bị tra tấn, đối xử hoặc trừng phạt tàn bạo, vô nhân đạo hoặc hạ nhục.

Tra tấn, đối xử hoặc trừng phạt tàn bạo, vô nhân đạo hoặc hạ nhục là một trong những hành vi vi phạm quyền con người nghiêm trọng nhất, một mặt gây ra những đau đớn về thể xác và tinh thần cho người bị áp dụng, mặt khác tác động tiêu cực đến việc bảo đảm tự do, công lí, hòa bình trên thế giới. Vì vậy, quyền được bảo vệ không bị tra tấn, đối xử hoặc trừng phạt tàn bạo, vô nhân đạo hoặc hạ nhục là một trong những quyền con người quan trọng được ghi nhận trong Điều 5 UDHR và cụ thể hóa trong Điều 7 ICCPR: "Không ai có thể bị tra tấn, đối xử hoặc trừng phạt tàn ác, vô nhân đạo hoặc hạ thấp nhân phẩm, không ai có thể bị sử dụng để làm thí nghiệm y học hoặc khoa học mà không có sự đồng ý tự nguyện của người đó”. Bên cạnh các quy định trên của UDHR và ICCPR, quyền bảo vệ không bị tra tấn đối xử hoặc trừng phạt tàn bạo, vô nhân đạo hoặc hạ nhục còn được đề cập một cách đầy đủ và rõ nét trong Công ước về chống tra tấn và các hình thức đối xử, trừng phạt tàn bạo, vô nhân đạo hoặc hạ thấp nhân phẩm (CAT, 1984). Bị can là đối tượng có khả năng cao bị áp dụng các biện pháp ngăn chặn tước quyền tự do, bị thẩm vấn bởi cơ quan công quyền nên tiềm ẩn nguy cơ bị tra tấn, đối xử trừng phạt tàn bạo, vô nhân đạo. Quyền được bảo vệ không bị tra tấn, đối xử hoặc trừng phạt tàn bạo, vô nhân đạo hoặc hạ nhục của bị can bao gồm các khía cạnh sau:

(1) Không ai được phép tra tấn, đối xử hoặc trừng phạt tàn bạo, vô nhân đạo hoặc hạ nhục bị can nhằm những mục đích như thu thập thông tin hoặc sự nhận tội từ người đó hay một người thứ ba, hoặc để trừng phạt người đó về một hành vi mà người đó hay người thứ ba đã thực hiện hoặc nghi ngờ đã thực hiện, để đe dọa hoặc ép buộc người đó hay người thứ ba, hoặc vì bất kỳ lí do gì khác dựa trên sự phân biệt đối xử dưới mọi hình thức khi mà sự đau đớn hoặc chịu đựng đó được gây ra bởi hoặc với sự xúi giục hoặc với sự đồng ý hoặc sự chấp nhận của một nhân viên công quyền hoặc người khác đang thực hiện công vụ. (không có bất kì hoàn cảnh ngoại lệ nào có thể biện minh cho việc tra tấn) (2) Hành vi tra tấn, đối xử hoặc trừng phạt tàn bạo, vô nhân đạo hoặc hạ nhục bị can phải bị trừng trị bằng các hình phạt thích đáng tương ứng với tính chất nghiêm trọng của chúng.

\subsection{Nhóm quyền được xét xủ công bằng}

Nhóm quyền được xét xử công bằng gắn liền với học thuyết Tố tụng công bằng (Due Process of Law). Tố tụng công bằng được xem như công cụ bảo vệ quyền lợi của cá nhân trước sự chuyên quyền của nhà nước. Quyền được xét xử công bằng được nhìn nhận ở nhiều khía 
cạnh: thứ nhất, quyền được xét xử công bằng là biểu hiện sự bình đẳng giữa các bên. Sự bình đẳng giữa các bên được hiểu rằng mỗi bên phải được trao những cơ hội hợp lí như nhau để trình bày ý kiến về vụ án- kể cả bằng chứng của bên đó, trong những điều kiện không bị đặt vào tư thế bất lợi hơn so với bên đối trọng $[6$, tr.96112] mọi sự đối xử thiên lệch đối với một bên trong tố tụng so với bên đối trọng là không chính đáng, bị cấm đoán và bị coi là vi phạm pháp luật; thứ hai là quyền được tranh tụng công bằng; thứ ba, yếu tố đảm bảo quyền được tiến hành tố tụng công bằng phụ thuộc vào trách nhiệm của cơ quan có thẩm quyền. Tòa án và các cơ quan tư pháp độc lập, không thiên vị là một nội dung quan trọng để bảo đảm công bằng. Quyền được xét xử công bằng là một quyền cơ bản và có tính phổ quát cao, là hòn đá tảng của các xã hội dân chủ. Quyền xét xử công bằng gồm tất cả quyền liên quan để bảo đảm cho quá trình tố tụng xử lí tội phạm và người phạm tội ở các giai đoạn trước xét xử và xét xử tại phiên tòa. Quyền được xét xử công bằng của bị can bao gồm các quyền cụ thể sau:

Thứ nhất, quyền bình đẳng truớc các co quan tu pháp

Bình đẳng là nền tảng quan trọng của xét xử công bằng. Bình đẳng trước cơ quan tư pháp đòi hỏi người tiến hành tố tụng lắng nghe ý kiến của các bên như một nền tảng của việc tìm kiếm sự thật, mọi sự thiên lệch đối với một bên trong tố tụng so với bên đối trọng là không chính đáng, bị cấm đoán và bị coi là vi phạm pháp luật. Quyền bình đẳng trước cơ quan tư pháp của bị can bao gồm hai nội dung: (1) Các bên tham gia tố tụng được đối xử không có sự phân biệt nào. Các bên buộc tội và gỡ tội có quyền ngang bằng trong việc đưa ra chứng cứ, quan điểm, yêu cầu; (2) Các cơ quan tư pháp độc lập, không thiên vị là một nội dung quan trọng để bảo đảm công bằng.

\section{Thư hai, quyền được suy đoán vô tọi}

Thuật ngữ suy đoán bắt nguồn từ tiếng $\mathrm{La}$ tinh, "praesumptino" được hiểu là coi vấn đề, hiện tượng nào đó đúng đắn cho đến khi chưa có lí do bác bỏ vấn đề, hiện tượng đó. Suy đoán vô tội là sự thể hiện quan điểm pháp lí khách quan, đó là Nhà nước, xã hội coi một người là công dân với các quyền và nghĩa vụ do pháp luật quy định, cho đến khi người đó chưa bị tòa án kết tội bằng một bản án có hiệu lực pháp luật [7, tr.21]. Suy đoán vô tội là cần thiết để tạo sự cân bằng hợp lí giữa lợi ích chung của xã hội và các quyền tự do cá nhân của con người. Sự cân bằng sẽ được thiết lập giữa quyền của bị cáo không bị xét xử oan sai và lợi ích của xã hội trong việc thực thi pháp luật [8, tr.147]. Suy đoán vô tội bảo vệ những người yếu thế trong tố tụng hình sự, bởi lẽ hoạt động tố tụng hình sự là một lĩnh vực khó khăn, phức tạp và nhạy cảm, liên quan đến các quyền thiết thực nhất của người bị tạm giữ, bị can, bị cáo vì vậy, người bị tạm giữ, bị can, bị cáo không bị coi là có tội nếu chưa có bản án kết tội của tòa án đã có hiệu lực pháp luật, là phương tiện pháp lí quan trọng chống lại những vi phạm có thể xảy ra đối với họ trong tố tụng hình sự [7, tr.28]. Quyền suy đoán vô tội được quy định tại khoản 2 Điều 14 ICCPR như sau: "Người bị cáo buộc là tội phạm hình sự có quyền được coi là vô tội cho tới khi hành vi phạm tội của người đó được chứng minh theo luật định". Nội hàm của quyền suy đoán vô tội của bị can bao gồm các nội dung sau:

Một là, bị can không bị coi là có tội khi chưa có bản án kết tội đã có hiệu lực pháp luật của tòa án. Bị can mới chỉ là người bị buộc tội về việc thực hiện những hành vi có dấu hiệu của tội phạm, còn vấn đề xác định bị can có tội hay không, tại thời điểm khởi tố bị can chưa xác định được mà sau đó, các cơ quan có thẩm quyền tiến hành tố tụng tiếp tục điều tra để xác định sự thật của vụ án nên phải đối xử với bị can như người chưa có tội.

Hai là, nghĩa vụ chứng minh thuộc về bên buộc tội, bị can có quyền nhưng không buộc phải chứng minh sự vô tội của mình. Các cơ quan có thẩm quyền tiến hành tố tụng hình sự khẳng định một người phạm tội thì các cơ quan này phải có nghĩa vụ chứng minh. Bị can có quyền chứng minh mình vô tội, họ có thể dùng quyền này bảo vệ mình, chứ không có nghĩa vụ chứng minh.

Ba là, mọi nghi ngờ về pháp luật và chứng cứ đều phải giải thích theo hướng có lợi cho bị can. Trong hoạt động tố tụng hình sự, có khả 
năng xảy ra những tình huống mà thông tin, chứng cứ về các sự kiện tình tiết cụ thể của vụ án liên quan đến lỗi của người bị buộc tội có mâu thuẫn, nên không thể kết luận, khẳng định một cách dứt khoát về sự kiện, tình tiết đó. Trong trường hợp không thể giải quyết nghi ngờ, trách nhiệm chứng minh thuộc về cơ quan công tố và bị can được hưởng lợi từ những sự nghi ngờ $[9$, tr.15]. Ba nội dung của quyền được suy đoán vô tội có quan hệ biện chứng, tác động qua lại lẫn nhau trong một chỉnh thể thống nhất.

\section{Thư ba, quyền bào chũa}

Xét về bản chất của tố tụng hình sự, các hoạt động cáo buộc của Nhà nước đối với cá nhân người bị buộc tội luôn thể hiện sự không cân bằng. Chính vì vậy, người bị buộc tội phải được trang bị những quyền pháp lí cần thiết để bảo vệ quyền và lợi ích chính đáng của mình, trong đó có quyền bào chữa. Trong TTHS, quyền bào chữa của người bị buộc tội là sự tự do bác bỏ buộc tội còn các cơ quan tiến hành tố tụng và những người tiến hành tố tụng có trách nhiệm tạo ra những điều kiện cần thiết để người bị buộc tội thực hiện sự tự do đó [10, tr.68]. Quyền bào chữa được ghi nhận tại Khoản 3 Điều 14 ICCPR. Theo đó, mọi người phải được các bảo đảm tối thiểu cho việc bào chữa bao gồm được biết lí do buộc tội, có đủ thời gian để chuẩn bị bào chữa và liên hệ với người bào chữa, được xét xử mà không bị trì hoãn, được đối chất với người làm chứng, được có phiên dịch miễn phí, không buộc đưa ra lời khai chống lại chính mình hoặc buộc phải nhận là mình có tội. Quyền bào chữa của bị can trong tố tụng hình sự bao gồm hai nội dung: quyền tự bào chữa của bị can và quyền có người bào chữa. Trong đó, quyền tự bào chữa của bị can là việc bị can tự mình sử dụng lí lẽ, chứng cứ, tài liệu nhằm chống lại việc buộc tội hoặc nhằm giảm nhẹ trách nhiệm hình sự hoặc bảo vệ quyền và lợi ích hợp pháp khác của mình. Quyền có người bào chữa bao gồm hai nội dung (1) Người bị buộc tội có quyền được nhờ người bào chữa để bảo vệ anh ta trước những cáo buộc của Nhà nước; (2) Nhà nước có nghĩa vụ cung cấp người bào chữa cho người bị buộc tội nếu anh ta không có khả năng thuê người tự bào chữa [11]. Hai nội dung của quyền bào chữa có tính độc lập tương đối nhưng cũng có quan hệ mật thiết với nhau, bị can có thể sử dụng một trong hai quyền này hoặc sử dụng đồng thời cả hai quyền trên.

Thí tu, quyền được yêu cầu bồi thường

Trong hoạt động tố tụng hình sự không thể tránh khỏi có trường hợp cơ quan tiến hành tố tụng khởi tố, điều tra, truy tô xét xử oan sai. Việc khắc phục bồi thường cho người bị oan sai cho các cơ quan tiến hành tố tụng gây ra là cần thiết nhằm khôi phục những thiệt hại vật chất, tinh thần cho người bị oan, trả lại công bằng xã hội. Do đó, quyền được yêu cầu bồi thường của người bị buộc tội là quyền chính đáng của họ, quyền này được ghi nhận khoản 6 Điều 14 ICCPR. Quyền được yêu cầu bồi thường của bị can bao gồm các nội dung: (1) Bị can bị thiệt hại do việc bắt, giam giữ, điều tra, truy tố, xét xử oan, sai có quyền yêu cầu được bồi thường. (2) Trách nhiệm bồi thường thiệt hại thuộc về Nhà nước. Trách nhiệm bồi thường của Nhà nước là trách nhiệm trực tiếp. Bởi vì hành vi của công chức là hành vi của Nhà nước nên nếu công chức có hành vi gây thiệt hại thì chính là Nhà nước gây thiệt hại [12, tr.72].

\section{Cơ chế bảo đảm quyền con người của bị can trong giai đoạn điều tra vụ án hình sự}

Cơ chế bảo đảm quyền con người trong tố tụng hình sự là tổng hợp các điều kiện có tính chất pháp lí để bảo đảm cho quyền con người được thực thi một cách đầy đủ nhất trong quá trình tố tụng giải quyết vụ án hình sự [13, tr.231]. Do đó, cơ chế bảo đảm quyền con người của bị can trong giai đoạn điều tra vụ án hình sự bao gồm các điều kiện có tính chất pháp lí bảo đảm cho quyền con người bị can được thực thi trong giai đoạn này như xây dựng pháp luật, thực thi pháp luật và giám sát việc thực thi pháp luật.

Thành tố đầu tiên trong cơ chế bảo đảm là xây dựng các quy định về bảo đảm quyền con người của bị can trong pháp luật tố tụng hình sự. Pháp luật tố tụng hình sự phải có các quy định đầy đủ, minh bạch, rõ ràng về các nguyên tắc cơ bản của TTHS, các quyền tố 
tụng của bị can, trách nhiệm của các cơ quan tiến hành tố tụng trong việc bảo đảm quyền con người của bị can, trình tự, thủ tục tố tụng điều tra, xử lí và chế tài đối với hành vi xâm phạm quyền con người.

Thành tố thứ hai là thực thi pháp luật về bảo đảm quyền con người của bị can trong giai đoạn điều tra vụ án hình sự. Thực thi pháp luật có ý nghĩa quyết định trong bảo đảm quyền con người. Các quy định pháp luật về bảo đảm quyền con người của bị can chỉ có thể phát huy được vai trò và những giá trị của mình khi nó được tôn trọng và thực hiện đầy đủ nghiêm minh trong thực tiễn. Nếu không bảo đảm được điều này thì các quy định đó chỉ là vô nghĩa. Thực thi pháp luật tố tụng hình sự là hành vi của các chủ thể có thẩm quyền điều tra nhằm hiện thực hóa các quy định của pháp luật tố tụng hình sự, làm cho chúng đi vào thực tiễn.

Thành tố thứ ba là giám sát việc thực hiện quyền con người của bị can trong giai đoạn điều tra vụ án hình sự. Giám sát việc thực hiện quyền con người của bị can trong giai đoạn điều tra là cần thiết và khách quan bởi tố tụng hình sự là hoạt động thực hiện quyền lực nhà nước liên quan trực tiếp đến các quyền cơ bản của con người nên đòi hỏi phải có sự giám sát chặt chẽ để các hoạt động trong lĩnh vực này luôn đúng pháp luật, bảo đảm tốt nhất các quyền và lợi ích hợp pháp của công dân. Nếu hoạt động tố tụng hình sự tiến hành một cách độc lập mà không có sự giám sát sẽ dẫn đến sự lạm quyền. Do đó, thiết lập cơ chế giám sát đối với hoạt động tố tụng hình sự điều kiện quan trọng để có thể bảo đảm quyền con người. Về nguyên tắc, hoạt động giám sát càng khách quan, công khai khi có sự tham gia của nhiều chủ thể giám sát. Do vậy, chủ thể thực hiện giám sát rất rộng, đó có thể là cơ quan nhà nước, tổ chức xã hội và mọi công dân. Giám sát thực hiện quyền con người của bị can trong giai đoạn điều tra được thực hiện qua các hình thức: (1) giám sát thông qua cơ quan quyền lực nhà nước; (2) giám sát của cơ quan chuyên trách; (3) giám sát của các tổ chức xã hội; (4) giám sát của công dân.

\section{Các yếu tố ảnh hưởng đến việc bảo đảm quyền con người của bị can}

Thể chế, chính sách

Đường lối chính trị, chính sách phát triển của một quốc gia là nhân tố quan trọng tác động trực tiếp đến quyền con người nói chung và quyền con người của bị can nói riêng. Chủ trương, đường lối chính sách của Đảng và Nhà nước giữ vai trò định hướng cho sự hình thành của pháp luật và các mặt kinh tế, xã hội, tổ chức bộ máy của một quốc gia. Nếu quốc gia có chủ trương, chính sách là xây dựng Nhà nước pháp quyền, thiết lập nền dân chủ thực sự và toàn diện vì con người, điều này sẽ định hướng đối với pháp luật cũng như các điều kiện kinh tế, xã hội, văn hóa, giáo dục, tổ chức bộ máy... bảo đảm cho con người phát triển toàn diện. Ngược lại, nếu quốc gia không xác định đường lối chính trị, chính sách phát triển vì con người thì ảnh hưởng tiêu cực đến việc xây dựng các quy định pháp luật cũng như các điều kiện kinh tế, xã hội khác.

\section{Pháp lí}

Yếu tố pháp lí là cơ sở, nền tảng cho việc bảo đảm quyền con người của bị can. Pháp luật là phương tiện chính thức hóa các giá trị xã hội của quyền con người, các quyền đó được pháp luật hóa và mang tính bắt buộc, được xã hội thừa nhận, bảo vệ. Quyền con người của bị can được quy định trong pháp luật thì nó sẽ trở thành quyền pháp định, là ý chí chung của toàn xã hội, được quyền lực Nhà nước tôn trọng và bảo vệ và bảo đảm bằng bộ máy, cách thức tác động của quyền lực nhà nước. Mọi hành vi xâm phạm đến quyền con người của bị can đều bị Nhà nước trừng trị thích đáng.

\section{Con người}

Có thể nói yếu tố con người có tính quyết định trong việc đảm bảo hiệu quả hoạt động của các cơ quan có thẩm quyền tiến hành tố tụng. Con người- đội ngũ cán bộ trong các cơ quan tư pháp- đóng vai trò cực kỳ quan trọng trong việc nâng cao hiệu quả hoạt động tư pháp nói chung, trong việc bảo vệ quyền con người nói riêng, vì suy cho đến cùng tất cả pháp luật, cơ chế, biện pháp đều là sản phẩm của con người $[14$, 
tr.165]. Hiệu quả của hoạt động bảo đảm quyền con người trong tố tụng hình sự nói chung và bị can trong giai đoạn điều tra nói riêng phụ thuộc vào các yếu tố như số lượng, chất lượng và đạo đức nghể nghiệp của người có thẩm quyền tiển hành tố tụng. Khi người tiến hành tố tụng bảo đảm đủ quân số, có trình độ chuyên môn nghiệp vụ vững chắc, có ý thức bảo vệ quyền con người, giữ gìn tư cách đạo đức trong sạch, lương tâm nghề nghiệp thì mới có thể xây dựng một nền tố tụng công minh, bình đẳng và vì con người.

\section{Các yếu tố khác}

+ Cơ cấu tổ chức và hoạt động cơ quan có thẩm quyền điều tra

Mô hình hoạt động của cơ quan điều tra là yếu tố quan trọng ảnh hưởng trực tiếp đến hiệu quả hoạt động điều tra tội phạm. Mô hình cơ quan điều tra có thể xây dựng theo hướng một cơ quan điều tra như Nhật Bản hoặc nhiều cơ quan có thẩm quyền tiến hành điều tra, mỗi cơ quan chịu trách nhiệm điều tra một loại vụ việc như Trung Quốc, Nga, Hoa Kỳ, Việt Nam. Tuy nhiên dù lựa chọn mô hình cơ quan điều tra như thế nào thì điều quan trọng là tổ chức cơ quan điều tra một cách hợp lí, bảo đảm thẩm quyền điều tra không bị chồng chéo đồng thời mô hình hoạt động của cơ quan điều tra phải xuất phát từ cơ sở khoa học của hoạt động điều tra tội phạm. Có như vậy, hoạt động điều tra mới khách quan, hiệu quả, đảm bảo tính nghiêm minh của pháp luật và bảo đảm quyền con người. Ngoài ra, cũng cần quan tâm đến mối quan hệ giữa cơ quan điều tra và cơ quan công tố để bảo đảm bảo tính chặt chẽ, thông suốt, hỗ trợ cho nhau trong công việc. Nếu là mối quan hệ phối hợp, chế ước thì các cơ quan có thẩm quyền một mặt phải đảm bảo tính độc lập trong việc thực hiện chức năng của mình, mặt khác cần có sự phối hợp với nhau để cùng thực hiện nhiệm vụ chung của TTHS. Nếu là mối quan hệ công tố chỉ đạo điều tra thì hoạt động của cơ quan điều tra buộc phải tuân thủ theo sự chỉ đạo của cơ quan công tố, có các quy định, biện pháp thích hợp để bảo đảm sự chấp hành của cơ quan điều tra.

+ Hoạt động tuyên truyền, phổ biến pháp luật

Đảm bảo quyền con người trong TTHS có mối quan hệ mật thiết với trình độ nhận thức và ý thức pháp luật của con người. Một trong những nguyên nhân dẫn đến những vi phạm về quyền con người của bị can là do trình độ nhận thức pháp luật chưa cao. Họ không đánh giá được tính hợp pháp trong hoạt động tố tụng của người có thẩm quyền tố tụng, không hiểu rõ quyền và nghĩa vụ của mình khi tham gia vào tiến trình tố tụng hình sự, thậm chí không biết mình bị vi phạm quyền con người. Vì vậy, đẩy mạnh tuyên truyền, giáo dục pháp luật để người tham gia tố tụng có nhận thức đúng đắn, đầy đủ về phạm vi, mức độ quyền, trên cơ sở đó thực hiện một cách đúng đắn và có hiệu quả các quyền mà pháp luật quy định cho họ sẽ góp phần bảo đảm quyền con người của bị can.

+ Cơ sở vật chất, trang thiết bị phục vụ hoạt động điều tra

Cơ sở vật chất, trang thiết bị kỹ thuật phục vụ hoạt động điều tra là một trong những yếu tố quan trọng bảo đảm thực thi quyền con người. Nhà nước cần quan tâm đầu tư cơ sở vật chất phục vụ hoạt động điều tra, tạm giữ, tạm giam và chế độ sinh hoạt của người bị buộc tội khi họ bị tạm giữ, tạm giam. Đó là một trong những thước đo sự bảo đảm quyền con người của bị can trong tố tụng hình sự. Mặt khác, đối với một số hoạt động điều tra, số lượng và chất lượng thông tin thu thập được một phần phụ thuộc vào sự hiện đại của phương tiện kỹ thuật hình sự. Do đó, nâng cấp, trang bị cơ sở vật chất, phương tiện kỹ thuật hiện đại sẽ giúp hoạt động điều tra diễn ra nhanh chóng, hiệu quả hơn, đồng thời hạn chế được khả năng xâm hại đến các quyền con người của bị can.

+ Cơ chế xử lí hành vi vi phạm quyền con người của bị can

Về nguyên tắc, hành vi vi phạm quyền con người bị xử lí một cách thích đáng, kịp thời mới có tác dụng răn đe những người khác không thực hiện hành vi tương tự. Đồng thời, nó giúp người bị xâm phạm tin tưởng vào sự công bằng, nghiêm minh của pháp luật. Do vậy, việc hình thành và vận hành cơ chế xử lí hành vi vi phạm quyền con người có vai trò quyết định hiệu quả của bảo đảm quyền con người của bị can trong giai đoạn điều tra vụ án hình sự. Mức độ và hình thức xử lí hành vi vi phạm quyền con người của bị can phụ thuộc vào điều kiện hoàn 
cảnh, chính sách hình sự của mỗi quốc gia nhưng phải tương xứng với tính chất và mức độ nguy hiểm của hành vi xâm phạm quyền con người của bị can đã gây ra, mang tính giáo dục nhưng cũng đồng thời mang tính răn đe. Có như vậy, quyền con người của bị can mới được bảo đảm một cách thực sự.

\section{Các yêu cầu đặt ra đối với việc bảo đảm quyền con người của bị can trong giai đoạn hiện nay}

Một là, bảo đảm quyền con người của bị can phải gắn liền với việc thực hiện đúng đường lối, chủ trương của Đảng, bám sát và phục vụ có hiệu quả các nhiệm vụ chính trị trong từng giai đoạn cách mạng. Đảm bảo quyền con người nói chung và bảo đảm quyền con người của bị can nói riêng là một trong những mục tiêu về con người mà Đảng và Nhà nước ta đã đề ra trong chiến lược phát triển kinh tế - xã hội. Là một yếu tố, bộ phận của các chính sách trong chiến lược của Đảng và Nhà nước, cho nên việc tăng cường các đảm bảo quyền con người của bị can không thể tách rời với việc thực hiện các mục tiêu, nhiệm vụ chính trị chung của đất nước, mà phải tiến hành đồng thời và chịu sự tác động, chi phối của các mục tiêu khác, trên cơ sở đó, góp phần thiết thực vào việc thực hiện các mục tiêu, nhiệm vụ cách mạng chung trong từng giai đoạn xây dựng và phát triển của đất nước.

Hai là, bảo đảm quyền con người của bị can phải gắn liền với việc xây dựng Nhà nước pháp quyền xã hội chủ nghĩa mà trong đó phải đáp ứng nội dung hết sức cơ bản đảm bảo pháp chế, tăng cường trách nhiệm của Nhà nước với công dân.

Ba là, bảo đảm quyền con người của bị can phải phù hợp với các tiêu chí về nhân quyền được ghi nhận trong pháp luật quốc tế. Các văn bản pháp lí về nhân quyền là thành tựu chung của nhân loại, là kết quả đấu tranh hàng nghìn năm của tư tưởng tiến bộ với các thế lực độc tài. Chuyển tải những tiêu chuẩn quốc tế về quyền con người nói chung trong tố tụng hình sự nói riêng vào pháp luật quốc gia thể hiện sự nhận thức tiến bộ, hợp quy luật của thời đại.
Bốn là, bảo đảm quyền con người của bị can trong giai đoạn điều tra vụ án hình sự phải gắn liền với việc ngăn ngừa có hiệu quả và xử lí kịp thời và nghiêm minh các loại tội phạm hình sự; bảo vệ trật tự, kỷ cương; bảo đảm và tôn trọng quyền dân chủ, quyền và lợi ích hợp pháp của các tổ chức và công dân.

\section{Một số giải pháp tăng cường bảo đảm quyền con người của bị can trong giai đoạn điều tra vụ án hình sự}

Nghiên cứu quy định của Bộ luật TTHS năm 2015, bên cạnh một số thay đổi, bổ sung tích cực nhằm bảo đảm quyền con người, vẫn còn có những quy định bât cập, chưa hợp lí. Do đó, giải pháp hàng đầu để tăng cường bảo đảm quyền con người của bị can là tiếp tục sửa đổi, bổ sung hoàn thiện hơn nữa các quy định của Bộ luật TTHS năm 2015 theo hướng sau đây:

Thứ nhất, Điều 13 Bộ luật TTHS năm 2015 về nguyên tắc suy đoán vô tội đề cập đến hai nội dung là: (1) Người bị buộc tội được coi là không có tội cho đển khi được chứng minh theo trình tự, thủ tục do Bộ luật TTHS quy định và có bản án kết tội của tòa án đã có hiệu lực pháp luật; (2) Khi không đủ và không thể làm sáng tỏ căn cứ để buộc tội, kết tội theo trình tự, thủ tục luật định thì cơ quan, người có thẩm quyền tiến hành tố tụng phải kết luận người bị buộc tội không có tội. Tuy nhiên, trong khoa học pháp lí, một số tác giả cho rằng ngoài những nội dung trên, nguyên tắc suy đoán vô tội còn bao hàm nội dung trách nhiệm chứng minh tội phạm thuộc về các cơ quan tiến hành tố tụng, người bị buộc tội có quyền nhưng không buộc phải chứng minh là mình vô tội $[15$, tr.171 và 16 , tr.111]. Chúng tôi đồng tình với quan điểm của các học giả này. Điều này có nguồn gốc từ quy định của Luật $\mathrm{La}$ mã cổ đại: "trách nhiệm chứng minh thuộc về người khẳng định, chứ không thuộc về người phủ định" [7, tr.52]. Cơ quan tiến hành tố tụng khẳng định một người phạm tội, thì cơ quan đó phải có trách nhiệm chứng minh. Người bị buộc tội là người phủ định mình không có tội, không có trách nhiệm chứng minh. Người bị buộc tội kể cả trong trường hợp họ có khả năng, điều kiện chứng 
minh mình vô tội thì đây không phải là trách nhiệm của họ. Ba nội dung của quyền được suy đoán vô tội có mối quan hệ biện chứng, tác động qua lại lẫn nhau, bổ sung cho nhau và đều nhằm mục đích chung là bảo vệ quyền con người. Thiếu nội dung kể trên nguyên tắc suy đoán vô tội không đảm bảo ý nghĩa nhân đạo, nhân văn sâu sắc của mình. Hiện nay, Bộ luật TTHS năm 2015 không thừa nhận nội dung này thuộc về nguyên tắc suy đoán vô tội mà coi đó là một nội dung của nguyên tắc xác định sự thật của vụ án. Chúng tôi cho rằng điều này không hợp lí vì nguyên tắc xác định sự thật khách quan đòi hỏi của cơ quan tiến hành tố tụng phải xác định đúng các tình tiết có thật của vụ án và đánh giá chúng dưới góc độ pháp lí thông qua việc thu thập, nghiên cứu, phân tích, đánh giá các chứng cứ một cách khách quan, toàn diện và đầy đủ $[17$, tr.12]. Trong mô hình tố tụng thiên về thẩm vấn mà Việt Nam đang theo đuổi, xác định sự thật của vụ án là trách nhiệm của Nhà nước, trách nhiệm này không chỉ bao gồm việc chứng minh tính có lỗi, các tình tiết tăng nặng trách nhiệm hình sự, tình tiết bất lợi khác của người bị buộc tội mà còn bao hàm cả việc chứng minh người bị buộc tội không có tội, không có lỗi, các tình tiết giảm nhẹ trách nhiệm hình sự, giảm nhẹ hình phạt của họ. Với cách quy định nguyên tắc xác định sự thật của vụ trong Bộ luật TTHS năm 2015, có thể thấy quy định đoạn 2 Điều 15 "Trong phạm vi nhiệm vụ, quyền hạn của mình, cơ quan có thẩm quyền tiến hành tố tụng phải áp dụng các biện pháp hợp pháp để xác định sự thật của vụ án một cách khách quan, toàn diện, đầy đủ, làm rõ chứng cứ xác định có tội và chứng cứ xác định vô tội, tình tiết tăng nặng và tình tiết giảm nhẹ trách nhiệm hình sự của người bị buộc tội” đã bao hàm hết các nội dung cơ bản của nguyên tắc này. Do vậy, chúng tôi kiến nghị tách nội dung "trách nhiệm chứng minh tội phạm thuộc về cơ quan có thẩm quyền tiến hành tố tụng, người bị buộc tội có quyền nhưng không buộc phải chứng minh là mình vô tội” khỏi nguyền tắc xác định sự thật của vụ án và bổ sung vào nguyên tắc suy đoán vô tội. Sự bổ sung này một mặt bảo đảm tính khoa học, đầy đủ về mặt nội dung của nguyên tắc suy đoán vô tội, đồng thời phù hợp quy định trong các Công ước quốc tế về quyền con người và pháp luật TTHS một số quốc gia tiến bộ trên thế giới.

Thứ hai, Bộ luật TTHS năm 2015 có nhiều thay đổi theo hướng mở rộng quyền của các chủ thể thực hiện chức năng bào chữa, tạo điều kiện cho việc gỡ tội, đối trọng có hiệu quả sự buộc tội của các cơ quan công quyền như bổ sung thêm quyền thu thập chứng cứ cho người bào chữa tuy nhiên người bị buộc tội lại không được quy định quyền này. Việc thu thập chứng cứ của người bào chữa nhằm mục đích bác bỏ, phủ nhận sự buộc tội của cơ quan điều tra, viện kiểm sát hoặc để giảm nhẹ tội lỗi của bị canthân chủ của họ. Về mặt nguyên tắc, các quyền năng pháp luật quy định cho người bào chữa là những quyền phái sinh từ quyền bào chữa của người bị buộc tội. Do đó, sẽ là không hợp lí khi quy định người bào chữa có quyền thu thập chứng cứ để bảo vệ quyền và lợi ích chính đáng của người bị buộc tội trong khi bản thân người bị buộc tội, chủ thể của quyền bào chữa lại không có quyền năng này. Để bảo đảm quyền tự bào chữa của người bị buộc tội nói chung và bị can nói riêng, đồng thời tương thích quyền tự bào chữa của người bị buộc tội và quyền bào chữa của người bào chữa, theo chúng tôi cần quy định người bị buộc tội có quyền thu thập chứng cứ. Theo đó, bổ sung Điều 88 như sau:

"1. giũu nguyên

2. giũ nguyên

3. Để thu thập chứng cú, ngườ bị buộc tội có quyền gặp bi hai, người làm chứng và nhũng người khác biết về vu án để hỏi, nghe ho trình bày về những vấn đề liên quan đến vu án, đề nghi co quan, tổ chức, cá nhân cung cấp tài liệu, đồ vật, dũ liệu điện tủ liên quan đến việc bào chũa."

Thứ ba, trong trường hợp bị can, bị cáo bị áp dụng thủ tục rút gọn, do thủ tục này bị rút ngắn về mặt thời gian nên quyền bào chữa của bị can, bị cáo không được bảo đảm. Thời hạn điều tra trong thủ tục rút gọn được quy định là 20 ngày kể từ ngày ra quyết định khởi tố vụ án. Đây thực sự là một thách thức và khó khăn lớn cho bị can trong việc chuẩn bị để tự bào chữa hoặc liên hệ và mời người bào chữa cho mình. Thời gian quá gấp gáp dẫn đến bị can không mời 
được người bào chữa hoặc không thể lựa chọn người bào chữa một cách cẩn thận, kỹ càng. Nghiên cứu các quy định của Luật TTHS quốc tế về quyền bào chữa, có thể thấy một trong những bảo đảm quan trọng của quyền bào chữa được quy định ở điểm $\mathrm{c}$ khoản 3 Điều 14 ICCPR là "được nhận sự trợ giúp pháp lí theo chỉ định trong trường hợp lợi ích của công lí đòi hỏi và không phải trả tiền cho sự trợ giúp pháp lí đó nếu không có đủ điều kiện trả”. Đoạn 10 Bình luận chung số 32 của HRC giải thích rõ hơn về nội dung này: "Việc có hay không có trợ giúp pháp lí dựa trên thực tế một người có thể hoặc không thể tiếp cận được các thủ tục tố tụng tố tụng hoặc tham gia vào quá trình tố tụng một cách thực chất." Như vậy, có thể thấy đối với trường hợp bị can không có điều kiện để thực hiện một quyền bào chữa một cách thực chất thì nên có những quy định và biện pháp pháp lí mang tính chất hỗ trợ đối với họ, đó là cho họ hưởng trợ giúp pháp lí chỉ định. Sự hưởng trợ giúp pháp lí chỉ định này xuất phát từ lợi ích của công lí đòi hỏi. Đối với bị can, bị cáo bị áp dụng thủ tục rút gọn có thể thấy rõ ràng là họ không có điều kiện để thực hiện quyền bào chữa của mình một cách thực sự. Nếu như bị can, bị cáo chưa thành niên hoặc có nhược điểm về thể chất hoặc tinh thần không có điều kiện chủ quan để thực hiện quyền bào chữa thì bị can, bị cáo bị áp dụng thủ tục rút gọn không đầy đủ điều kiện khách quan để thực hiện quyền bào chữa ${ }^{1}[18$, tr.56]. Do vậy, chúng tôi đồng ý với quan điểm của một số học giả cho rằng trường hợp bị can, bị cáo bị áp dụng thủ tục rút gọn cần được coi là trường hợp bắt buộc có người bào chữa tham gia trong vụ án" $[19$, tr.49 và 18, tr.56].

Thứ tư, căn cứ áp dụng biện pháp ngăn chặn tạm giam tại khoản 1 Điều 119 Bộ luật TTHS năm 2015 được quy định như sau "Tạm giam có thể áp dụng với bị can, bị cáo về tội đặc biệt nghiêm trọng và rất nghiêm trọng". Theo căn cứ này, việc áp dụng biện pháp ngăn chặn tạm giam dựa trên tính chất và mức độ nguy hiểm cho xã hội của hành vi phạm tội mà không cần

\footnotetext{
${ }^{1}$ Phan Thị Thanh Mai (2012), Hoàn thiện pháp luật hình sự nhằm hạn chế việc phải chuyển từ thủ tục rút gọn sang thủ tục chung để giải quyết vụ án, Tạp chí Luật học,6, tr 56.
}

chứng minh khả năng trốn tránh, gây khó khăn cho hoạt động điều tra, truy tố, xét xử và tiếp tục phạm tội của bị can, bị cáo. Tuy nhiên, có những bị can, bị cáo phạm tội rất nghiêm trọng và đặc biệt nghiêm trọng sau khi bị phát hiện ra hành vi phạm tội thì ăn năn hối cải, thành khẩn khai báo, khắc phục hậu quả để hưởng sự khoan hồng của pháp luật. Do đó, không thể lấy tính chất, mức độ nguy hại cho xã hội cao hay thấp của hành vi phạm tội để suy đoán bị can, bị cáo có khả năng trốn tránh việc truy cứu trách nhiệm hình sự hay gây khó khăn, trở ngại cho quá trình giải quyết vụ án. Việc xác định căn cứ áp dụng biện pháp ngăn chặn phải xuất phát từ bản chất và mục đích của biện pháp ngăn chặn. Trong khoa học pháp lí, phần lớn các học giả cho rằng căn cứ áp dụng biện pháp ngăn chặn là những tài liệu chứng cứ dự báo có đầy đủ cơ sở về khả năng bị can, bị cáo sẽ gây khó khăn cho việc điều tra, truy tố, xét xử, thi hành án và tiếp tục phạm tội [20, tr.55]. Vì vậy, căn cứ áp dụng biện pháp ngăn chặn tạm giam phải là căn cứ có thật dự báo khả năng thực tế có thể xảy ra việc bị can, bị cáo bỏ trốn hoặc cản trở hoạt động tố tụng hay tiếp tục gây án chứ không phải suy diễn từ tính chất và mức độ nguy hiểm cho xã hội của hành vi mà họ bị cho là đã thực hiện. Việc suy diễn tùy tiện trong lập pháp tạo ra các kẽ hở pháp lí cho các hành vi xâm phạm quyền con người, quyền và lợi ích hợp pháp của các cá nhân. Đồng thời, việc áp dụng biện pháp ngăn chặn cần sự khẩn trương, nhanh chóng để đạt được mục đích ngăn chặn, sẽ là khó khăn khi buộc các cơ quan có thẩm quyền xác định hành vi phạm tội đó thuộc loại ít nghiêm trọng, nghiêm trọng hay rất nghiêm trọng, đặc biệt nghiêm trọng khi quyết định áp dụng biện pháp này. Vì vậy, chúng tôi cho rằng căn cứ áp dụng biện pháp tạm giam chỉ nên dựa trên hình phạt Bộ luật hình sự (BLHS) quy định đối với tội danh đó là hình phạt tù trên 2 năm và căn cứ thực tế cho thấy người bị buộc tội tiếp tục phạm tội hoặc cản trở, gây khó khăn cho việc điều tra, truy tố, xét xử, thi hành án. Theo đó, Điều 119 Bộ luật TTHS cần được sửa đổi như sau:

"Tạm giam có thể được áp dụng đối với bi can, bị cáo phạm tội mà BLHS quy định hình 
phạt tù trên 2 năm khi có căn cứ xác định người đó thuộc một trong các truoòng hợp:

$a$.

b.

c....."

Thứ năm, về thẩm quyền áp dụng biện pháp ngăn chặn tạm giam. Trong quy định của Bộ luật TTHS năm 2015, thủ trưởng, phó thủ trưởng cơ quan điều tra được ra lệnh tạm giam, lệnh tạm giam của những người này phải được Viện kiểm sát phê chuẩn trước khi thi hành. So sánh với thông lệ quốc tế và pháp luật một số quốc gia khác, chỉ một số quốc gia như Trung Quốc, Việt Nam giao Cơ quan điều tra thẩm quyền quyết định áp dụng biện pháp tạm giam [21, tr.29]. Các quốc gia khác như Nga, Pháp, Đức, Nhật Bản, Tòa án là cơ quan duy nhất được trao quyền quyết định việc tạm giam trên cơ sở hồ sơ, tài liệu có liên quan của cảnh sát và đề nghị của Công tố viên $[22, \operatorname{tr} .79 ; 23$, tr.114; 24 , tr. 118 và 25 , tr.13]. Quy định như vậy nhằm mục đích đặt cơ quan điều tra dưới sự kiểm soát của cơ quan xét xử [26, tr.23]. Chúng tôi cho rằng hoạt động điều tra nói chung và việc áp dụng biện pháp ngăn chặn nói riêng phải đặt dưới sự kiểm soát là vô cùng cần thiết đặc biệt đối với giai đoạn điều tra trong mô hình tố tụng thiên về thẩm vấn đang tồn tại ở Việt Nam. Bởi lẽ trong mô hình tố tụng thẩm vấn này, giai đoạn điều tra mang các đặc trưng như bán công khai, tính tranh tụng, sự bình đẳng về quyền và nghĩa vụ các bên hạn chế. Do vậy, nếu giao quá nhiều quyền lực nhà nước cho cơ quan điều tra, việc lạm quyền dễ xảy ra nhưng lại khó bị phát hiện. Bởi sự lạm quyền là thuộc tính của những người gắn với quyền lực nhà nước. Ở đâu có quyền lực, thì ở đó luôn tiềm ẩn nguy cơ của sự lạm quyền [27, tr.34]. Sự lạm quyền trong việc áp dụng biện pháp ngăn chặn tạm giam có khả năng gây hậu quả nghiêm trọng, ảnh hưởng đến quyền tự do thân thể, một trong những quyền con người cơ bản của bị can. Với cơ chế kiểm soát việc áp dụng biện pháp ngăn chặn tạm giam hiện nay trong Bộ luật TTHS năm 2015 là Thủ trưởng, Phó Thủ trưởng cơ quan điều tra được ra lệnh tạm giam nhưng lệnh này phải được sự phê chuẩn của viện kiểm sát trước khi thi hành theo chúng tôi chưa đủ mạnh. Cơ chế kiểm soát này phải được nâng cao theo hướng cơ quan điều tra chỉ được quyền đề nghị còn viện kiểm sát sẽ quyết định việc áp dụng biện pháp tạm giam. Do đó, chúng tôi đề nghị cần bỏ thẩm quyền quyết định tạm giam của Thủ trưởng, Phó Thủ trưởng cơ quan điều tra. Trong trường hợp cần thiết, cơ quan điều tra có quyền đề nghị ra lệnh tạm giam còn thẩm quyền ra lệnh tạm giam thuộc về Viện trưởng, Phó Viện trưởng Viện kiểm sát. Như vậy, số lượng đối tượng có thẩm quyền quyết định việc tạm giam giảm từ 9 loại đối tượng xuống còn 7 đối tượng. Điều này không những phù hợp với tinh thần Nghị quyết số 49NQ/TW "thu hẹp đối tượng, người có thẩm quyền quyết định áp dụng biện pháp tạm giam”, mà còn hợp với xu hướng chung của các quốc gia trên thế giới và bảo đảm tốt hơn nữa quyền bất khả xâm phạm về thân thể của bị can.

Thứ sáu, thời hạn áp dụng biện pháp ngăn chặn tạm giam trong trường hợp vụ án được điều tra bồ sung chưa phù hợp. Nghiên cứu các căn cứ để trả hồ sơ để điều tra bổ sung được quy định tại khoản 1 Điều 245 có thể thấy các căn cứ này dựa trên những sai phạm và thiếu sót của cơ quan điều tra trong quá trình điều tra vì vậy các cơ quan này phải tự mình khắc phục những thiếu sót sai lầm đó, bị can không có lỗi trong trường hợp này. Tuy nhiên, bị can đã bị tạm giam trong giai đoạn điều tra ban đầu, nay theo quy định của khoản 4 điều 174 Bộ luật TTHS năm 2015 lại bị tiếp tục tạm giam trong thời hạn điều tra bổ sung. Điều này không công bằng với bị can vì bị can bị hạn chế quyền tự do vì những sai phạm của cơ quan có thẩm quyền tiến hành điều tra. Do đó, để bảo đảm bị can không bị tạm giam quá dài, đồng thời nâng cao tinh thần, trách nhiệm của cơ quan có thẩm quyền điều tra trong việc xác định sự thật của vụ án, cần thiết phải sửa đổi quy định về thời hạn tạm giam khi điều tra bổ sung theo hướng không cho phép tạm giam bị can nếu thời hạn tạm giam trong điều tra vụ án trước đó đã hết thời hạn tạm giam tối đa theo luật định. Theo đó, khoản 4 Điều 174 được sửa đổi như sau:

"4. Khi phục hồi điều tra, điều tra bổ sung, điều tra lại, Cơ quan điều tra có quyền thay đổi, 
áp dụng, hủy bỏ biện pháp ngăn chặn, biện pháp cưỡng chế theo quy định của Bộ luật này.

Trường hợp có căn cứ theo quy định của Bộ luật này cần tạm giam trong khi điều tra bổ sung thì tổng thời hạn tạm giam không được vượt quá thời hạn tạm giam được quy định tại Điều 173 của Bộ luật này.

Thời hạn tạm giam và gia hạn tạm giam trong trường hợp vụ án được điều tra lại được thực hiện theo quy định tại Điều 173 của Bộ luật này"

Thứ bảy, trường hợp người bào chữa không thể thu thập được chứng cứ thì người bào chữa có thể đề nghị cơ quan có thẩm quyền tiến hành tố tụng thu thập nhưng Điều 81 Bộ luật TTHS năm 2015 không quy định về trách nhiệm của cơ quan có thẩm quyền tiến hành tố tụng phải thực hiện đề nghị thu thập chứng cứ của người bào chữa. Điều đó làm cho điều luật thiếu tính chặt chẽ, không bảo đảm quyền của người bào chữa. Để nâng cao tinh thần trách nhiệm của cơ quan điều tra trong trường hợp nhận được đề nghị thu thập chứng cứ từ người bào chữa, người bị buộc tội, góp phần bảo đảm quyền bào chữa cho những đối tượng này, chúng tôi kiến nghị bổ sung khoản 3 Điều 81 như sau:

"Điều 81. Thu thập, giao chúng cú, tài liệu, đồ vật liên quan đến việc bào chũa

1. (giũ nguyên)

2. (gĩ்̃ nguyên)

3. Truòng hợp không thể thu thập được chứng cú, tài liệu, đồ vật liên quan đến việc bào chũa thì người bi buộc tội, người bào chũa có thể đề nghị cơ quan có thẩm quyền tiến hành tố tụng thu thập. Co quan có thẩm quyền tiến hành tố tụng phải thực hiện yêu cầu của người bị buộc tội, người bào chũa, nếu không thưc hiện được phải trả lời và nói rõ lí do."

Thứ tám, theo quy định tại khoản 2 Điều 9 Công ước về các quyền dân sự chính trị năm 1966 thì "Bất cứ người nào bị bắt giữ đều phải được thông báo, vào lúc bị bắt, vì những lí do người đó bị bắt và phải được thông báo không chậm trễ về bất kỳ sự buộc tội nào đối với người đó”. Như vậy, quyền được thông báo vì lí do bị bắt, giữ là quyền cơ bản của con người được ghi nhận trong các Văn bản pháp lí quốc tế về quyền con người. Việc bảo đảm quyền này đặt ra nghĩa vụ cho cơ quan có thẩm quyền tiến hành tố tụng phải thông báo, giải thích vì lí do và sự buộc tội đối với người bị bắt, giữ. Nghĩa vụ đó phải được ghi nhận trong pháp luật TTHS làm cơ sở để các cơ quan có thẩm quyền tiến hành tố tụng phải tuân thủ nghiêm chỉnh trong khi giải quyêt vụ án hình sự. Tuy nhiên, đối với các biện pháp ngăn chặn như giữ người trong trường hợp khẩn cấp, bắt quả tang, bắt người đang bị truy nã, tạm giam thì Bộ luật TTHS năm 2015 lại chưa có quy định về thông báo, giải thích lí do bị bắt, giữ. Theo ý kiến chúng tôi, để tăng tính minh bạch và để thực hiện nghiêm chỉnh hoạt động này, Bộ luật TTHS năm 2015 cần phải có quy định lập biên bản về việc thông báo, giải thích quyền và nghĩa vụ của những người trên, họ phải ký xác nhận là đã được giải thích các quyền và nghĩa vụ theo quy định của pháp luật. Các biên bản này phải được lưu tại hồ sơ vụ án như một quy định bắt buộc.

Thứ chín, đối với trường hợp giải quyết yêu cầu, đề nghị khác của người tham gia tố tụng, Bộ luật TTHS năm 2015 quy định trách nhiệm của của cơ quan này trong việc giải quyết yêu cầu đề nghị đó, nhưng lại không quy định về thời hạn trả lời về việc tiếp nhận yêu cầu, đề nghị cũng như thời hạn giải quyết đến hệ quả là các cơ quan tiến hành tố tụng có thể chậm trễ hoặc cố tình trì hoãn việc giải quyết các yêu cầu, đề nghị trên, ảnh hưởng đến quyền của người tham gia tố tụng trong đó có bị can. Do vậy, cần phải quy định chặt chẽ về thời hạn cơ quan có thẩm quyền tiến hành tố tụng giải quyết các yêu cầu, đề nghị của người tham gia tố tụng. Theo ý kiến chúng tôi, thời hạn tiếp nhận để trả lời về việc có đồng ý hay không đồng ý với đề nghị của người tham gia tố tụng là 02 ngày, thời hạn giải quyết yêu cầu, đề nghị là 10 ngày kể từ ngày tiếp nhận. Theo đó, khoản 1 Điều 175 được sửa đổi như sau:

"Khi người tham gia tố tụng có yêu cầu, đề nghi về nhũng vấn đề liên quan đến vu án thì Co quan điều tra, co quan được giao nhiệm vu tiến hành một số hoạt động điều tra, Viện kiểm sát tiếp nhận yêu cầu, đề nghị đó. Trong thời hạn 02 ngày kể tù ngày nhận được yêu cầu, Co 
quan điều tra, cơ quan đươc giao nhiệm vu tiến hành một số hoạt động điè̀u tra hoạc Viện kiểm sát phải trả lời về việc chấp nhận hay không chấp nhận yêu cầu và nêu rõ lí do. Trường hợp châp nhận yêu cầu, Co quan điều tra, co quan được giao nhiệm vu tiến hành một số hoạt động điều tra hoạc Viện kiểm sát trong phạm vi trách nhiệm của mình phải trả lời đề nghị đó trong thời hạn 10 ngày và báo cho ho biết kết quả."

Bên cạnh giải pháp về pháp luật, tăng cường năng lực cán bộ điều tra, kiểm sát trên các phương diện số lượng, chất lượng, đạo đức góp phần nâng cao chất lượng hoạt động điều tra, một mặt bảo đảm hoạt động điều tra khách quan, đúng pháp luật, mặt khác bảo đảm quyền con người của bị can. Bên cạnh đó, việc đổi mới cơ sở vật chất, trang thiết bị hiện đại phục vụ hoạt động điều tra đóng vai trò không nhỏ giúp hoạt động điều tra diễn ra nhanh chóng, hiệu quả hơn. Đồng thời, đẩy mạnh tuyên truyền, trang bị kiến thức pháp luật cho người dân cũng là giải pháp quan trọng giúp họ có phương tiện bảo vệ chính mình khi bước vào vòng xoay tố tụng.

\section{Tài liệu tham khảo}

[1] Hiến pháp năm 2013, NXB Chính trị Quốc gia Sự thật, năm 2018.

[2] Lê Hữu Thể, Đỗ Văn Đương, Nguyễn Thị Thủy, Những vấn đề lí luận và thực tiễn cấp bách của việc đổi mới thủ tục tố tụng hình sự đáp ứng yêu cầu của cải cách tư pháp, NXB Chính trị Quốc gia, năm 2013.

[3] Nguyễn Như Ý (chủ biên), Đại từ điển tiếng Việt, NXB Đại học Quốc gia Thành phố Hồ Chí Minh, năm 2010.

[4] Montesquieu, Tinh thần pháp luật, NXB Giáo dục, Hà Nội, năm 1996.

[5] Trần Quang Tiệp, Về bảo đảm quyền và lợi ích hợp pháp của người bị tạm giữ, bị can, bị cáo trong tố tụng hình sự, NXB Chính trị Quốc gia, năm 2009.

[6] Salvatore Zappalà, Human rights in criminal proceedings, Oxford, 2005.

[7] Nguyễn Thành Long, Nguyên tắc suy đoán vô tội trong luật tố tụng hình sự Việt Nam, NXB Chính trị Quốc gia, năm 2011.
[8] David Hamer, The Presumption of Innocence and Reverse Burdens : A Balancing Act, Cambridge Law Journal, 2007.

[9] Lawyers Committee for Human Rights, What is a fair trial?, New York, 2000.

[10] Phạm Hồng Hải, Bảo đảm quyền bào chữa của người bị buộc tội, NXB Công an Nhân dân, năm 1999.

[11] Felix Rackow, The right to counsel: English and America Precedent, The William and Mary Quaterly, 1954, Third Series, Vol.11, No1.

[12] Nguyễn Văn Tuân, Bảo đảm quyền được bồi thường của người bị thiệt hại, NXB Tư pháp, năm 2016.

[13] Nguyễn Ngọc Chí, Quyền con người trong lĩnh vực tư pháp hình sự, NXB. Hồng Đức, năm 2016.

[14] Vũ Văn Nhiêm, Một số vấn đề về bảo vệ quyền con người trong tố tụng hình sự Việt Nam, sách chuyên khảo Bảo đảm quyền con người trong tư pháp hình sự Việt Nam, NXB Đại học Quốc gia Thành phố Hồ Chí Minh, năm 2010.

[15] Trịnh Quốc Toản (2004), Hoàn thiện Bộ luật tố tụng hình sự bảo đảm nguyên tắc suy đoán vô tội, Cải cách tư pháp trong giai đoạn xây dựng nhà nước pháp quyền, NXB Đại học Quốc gia, năm 2004.

[16] Lê Văn Cảm, Những vấn đề cơ bản trong khoa học luật hình sự, NXB Đại học Quốc gia, năm 2005.

[17] Trần Thị Thu Hiền, Nguyên tắc xác định sự thật của vụ án trong tố tụng hình sự, Luận văn thạc sĩ luật học, năm 2011.

[18] Phan Thị Thanh Mai, Hoàn thiện pháp luật hình sự nhằm hạn chế việc phải chuyển từ thủ tục rút gọn sang thủ tục chung để giải quyết vụ án, Tạp chí Luật học, 6/2012.

[19] Nguyễn Văn Hoàn, Mấy ý kiến về thủ tục rút ngắn, trong cuốn "Những vấn đề lí luận và thực tiễn cấp bách của tố tụng hình sự Việt Nam", Viện Kiểm sát Nhân dân Tối cao, năm 1995.

[20] Trần Quang Tiệp, Về tự do cá nhân và biện pháp cưỡng chế trong tố tụng hình sự, NXB Chính trị Quốc gia, năm 2011.

[21] Viện Khoa học Kiểm sát, BLTTHS nước Cộng hòa nhân dân Trung Hoa, năm 2012.

[22] Viện Khoa học Kiểm sát, BLTTHS Liên Bang Nga, năm 2012.

[23] Viện Khoa học Kiểm sát, BLTTHS Cộng hòa Liên bang Đức, năm 2012.

[24] Viện Khoa học Kiểm sát, BLTTHS Pháp, năm 2012.

[25] Viện Khoa học Kiểm sát, BLTTHS Nhật Bản, năm 2012.

[26] Tô Văn Hòa (chủ biên), Những mô hình tố tụng hình sự điển hình trên thế giới, NXB Hồng Đức, năm 2012.

[27] Nguyễn Đăng Dung, Nhà nước và trách nhiệm của nhà nước, NXB Tư pháp, năm 2006. 